DOI: 10.12731/2658-6649-2019-11-5-74-80

УДК 616-006.4

\title{
ИСПОЛЬЗОВАНИЕ ДНК, ВЫДЕЛЕННОЙ ИЗ ОБРАЗЦОВ КОСТНОГО МОЗГА В ПАРАФИНОВЫХ БЛОКАХ ОТ ПАЦИЕНТОВ С ХМН, ДЛЯ АНАЛИЗА СОМАТИЧЕСКИХ МУТАЦИЙ
}

Курочкин Д.В., Карнюшка А.А., Субботина Т.Н., Хазиева А.С., Гаркуша Т.А., Петриченко Т.Ю., Хоржевский В.А.

Хронические миелопролиферативные неоплазмы (ХМН) - клональные заболевания, характеризующиеся нарушением пролиферации миелоидной линии клеток в костном мозге. Для подтверждения диагноза и определения фенотипической формы, ВОЗ рекомендуется проведение молекулярно-генетических исследований. Предполагается, что исследование ДНК, выделенной из костного мозга в парафиновых блоках от тринегативных пациентов с XMH, позволит выявить соматические мутации (в генах $J A K 2$, CALR, MPL), ассочиированные с XMH. В данной работе показано, что ДНК из костного мозга в парафиновых блоках от пациентов с ХМН пригодна для генетических исследований.

Ключевые слова: calr; хронические миелопролиферативные неоплазии.

\section{USE OF DNA ISOLATED FROM BONE MARROW SAMPLES IN PARAFFIN BLOCKS FROM PATIENTS WITH MPN TO ANALYZE SOMATIC MUTATIONS}

Kurochkin D.V., Karnyushka A.A., Subbotina T.N., Garkusha T.A., Khazieva A.S., Petrichenko T.J., Khorzhevsky V.A.

Myeloproliferative neoplasms (MPN) are a clonal disease characterized by impaired proliferation of myelopoietic cell lines. WHO recommends molecular genetic studies to confirm the diagnosis and determine the phenotypic form. It is assumed that the study of DNA isolated from bone marrow in paraffin blocks from triple-negative patients with MPN will reveal somatic mutations (in JAK2, CALR, MPL genes) associated with MPNThis study shows that bone marrow DNA in paraffin blocks from patients with MPN is suitable for genetic studies.

Keywords: calr; myeloproliferative neoplasms. 


\section{Введение}

Хронические миелопролиферативные неоплазии (ХМН) - клональные заболевания, характеризующиеся нарушением пролиферации миелоидной линии клеток в костном мозге. К ХМН относят истинную полицитемию, эссенциальную тромбоцитемию и первичный миелофиброз.

В настоящее время достоверно установлена центральная роль соматических мутаций гемопоэтической стволовой клетки при этих патологиях: в гене янус-киназы $(J A K 2)$, в гене рецептора тромбоэтинового рецептора $(M P L)$, в гене кальретикулина $(C A L R)$.

Морфологическое исследование трепанобиоптата костного мозга-один

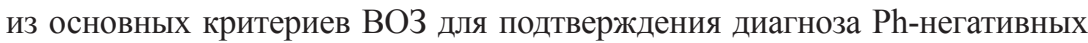
$\mathrm{XMH} \mathrm{[1,} \mathrm{с.} \mathrm{235-242],} \mathrm{однако} \mathrm{не} \mathrm{всегда} \mathrm{метод} \mathrm{позволяет} \mathrm{однозначно} \mathrm{сделать}$ вывод о наличии ХМН или определиться с его фенотипической формой.

Предполагается, что исследование ДНК, выделенной из костного мозга в парафиновых блоках от тринегативных пациентов с XМН, позволит выявить соматические мутации (в генах JAK2, CALR, MPL), ассоциированные с XMH.

Поскольку в костном мозге ДНК имеется у представителей всех клеточных линий миелопоэза, то исследование ДНК, выделенной из костного мозга в парафиновых блоках от тринегативных пациентов с ХMН, возможно позволит выявить соматические JAK2, CALR и MPL мутации, ассоциированые с ХMН. Также возможность выявления этих и других мутаций в ДНК, выделенной из исследуемых образцов костного мозга в парафиновых блоках, может помочь врачу в дифференциальной диагностике между $\mathrm{XMH} \mathrm{и} \mathrm{вторичными} \mathrm{эритро-} \mathrm{и/или} \mathrm{тромбоцитозами,} \mathrm{при} \mathrm{невозможности}$ исследовать мутационный статус из образцов периферической крови в силу различных обстоятельств.

Таким образом, цель данной работы - оценка возможности использования ДНК, выделенной из образцов костного мозга в парафиновых блоках, с целью скринингового анализа соматических $C A L R$ мутаций при использовании гетеродуплексного анализа с последующим электрофорезом в ПААГ у пациентов с ХМН.

\section{Материалы и методы}

В исследование были включены 3 пациента с диагнозом ХМН. Диагноз МФ у первого и второго пациентов и ИП у третьего пациента были подтверждены морфологическим исследованием трепанобиоптата костного мозга. Объектом исследования в настоящей работе являлись образцы ДНК от пациентов №1, №2 и №3, выделенные как из парафиновых блоков костного мозга, так и из лейкоцитов цельной крови. 
ДНК из лейкоцитов крови выделяли с использованием набора реагентов GeneJET ${ }^{\mathrm{TM}}$ (ThermoFisherScientific). ДНК из парафиновых блоков костного мозга выделяли с использованием набора реагентов GeneJET ${ }^{\mathrm{TM}} \mathrm{FFPE}$ DNA PurificationKit (ThermoFisherScientific).

Скрининговое исследование наличия мутаций в гене $C A L R$ проводили при использовании гетеродуплексного анализа с последующим электрофорезом в ПААГ, который ранее был предложен специалистами научно-практической лаборатории молекулярно-генетических методов исследований СФУ [2, с. 29-33]. Участок гена CALR (265 bp) амплифицировали используя праймеры $C A L R \_\mathrm{F}$ (5'ggcaaggccctgaggtg-3') и $C A L R \_\mathrm{R}$ (5'ggcctcagtccagcctg-3), заимствованные из статьи [3, с. 79-84].

\section{Результаты исследования}

По результатам электрофореза в 8\% ПААГ трёх испытуемых образцов ДНК можно отметить, что основные специфические для анализируемых CALR мутаций полосы на дорожках от образцов ДНК, выделенных из костного мозга в парафиновых блоках, соответствуют полосам на соответствующих дорожках от образцов ДНК, выделенных из лейкоцитов цельной крови, но интенсивность свечения несколько ниже. В одной из дорожек наблюдаются полосы от неспецифических продуктов амплификации.

\section{Обсуждение}

Морфологическое исследование трепанобиоптата является важным исследованием и рекомендовано ВОЗ при постановке диагноза Ph-негативное ХМН. Однако кроме морфологического исследования в некоторых случаях для подтверждения диагноза может быть востребован молекулярно-генетический анализ в образцах ДНК из костного мозга в парафиновых блоках на предмет наличия мутаций, ассоциированных с ХМН и рекомендуемых ВОЗ.

Показанная в данной работе более низкая интенсивность свечения полос (продуктов амплификации ДНК) на дорожках от образцов ДНК, выделенных из костного мозга в парафиновых блоках, в сравнении с полосами на соответствующих дорожках от образцов ДНК, выделенных из лейкоцитов цельной крови, по-видимому, обусловлено более низкой концентрацией специфических участков ДНК для амплификации, полученных при выделении из костного мозга. Причиной этого могут являться такие факторы, как воздействие химических реагентов, используемых при приготовлении блоков, и длительность хранения парафиновых блоков. Появление неспецифических продуктов амплификации на дорожке от одного 
из образцов ДНК обусловлено фрагментацией ДНК, индуцируемой фиксацией формалином [4, с. 957-964]. Фрагментация может снижать количество ДНК, подходящей для амплификации методом ПЦР, что вынуждает добавлять большее количество ДНК в ПЦР-смесь.

\section{Заключение}

На данном этапе работы нами установлено, что несмотря на относительно низкий выход ДНК при выделении её набором реагентов «GeneJET FFPE DNA PurificationKit» из парафиновых блоков костного мозга, по сравнению с выходом при выделении ДНК из клеток периферической крови, полученные результаты позволяют сделать вывод, что ДНК из костного мозга в парафиновых блоках от пациентов с ХМН пригодна для генетических исследований, в частности для выявления соматических мутаций в гене CALR.

В дальнейшем считаем важным провести сравнительную оценку уровня аллельной нагрузки соматическими мутациями в образцах ДНК, полученных в одно и то же время, и от одних и тех же пациентов, как из клеток периферической крови, так и из клеток костного мозга в парафиновых блоках. Если уровень аллельной нагрузки в образцах ДНК из костного мозга будет значительно выше, то предполагаем, что это позволит в дальнейшем выявлять известные соматические мутации у тринегативных пациентов с диагнозом ХМН, что в свою очередь улучшит диагностику ХМН.

Информация о конфликте интересов. Авторы заявляют об отсутствии конфликта интересов.

Информация о спонсорстве. Исследование не имело спонсорской поддержки.

\section{Список литературы}

1. Соколова М.А. Современный представления о «классических» $\mathrm{PH}$ - нагативных хронических миелопролиферативных заболеваниях // Клиническая онкогематология. 2010. №3 (3). С. 235-242.

2. Использование гетеродуплексного анализа и пиросеквенирования в алгоритме диагностики истинной полицитемии, ассоциированной с соматическими мутациями в 12 экзоне гена ЈАК 2 / Т.Н. Субботина, А.Е. Харсекина, Е.А. Дунаева [и др.] // Лабораторная служба. 2017. №1 (6). С. 29-33.

3. An accurate, simple prognostic model consisting of age, JAK2, CALR, and MPL mutation status for patients with primary myelofibrosis / U. Rozovski, S. Verstovsek, T. Manshouri [et al.] // Haematologica. 2017. V. 102. N. 1, pp. 79-84. 
4. Genome-wide copy number alterations detection in fresh frozen and matched FFPE samples using SNP 6.0 arrays / M. Tuefferd, A.D. Bondt, I.V.D. Wyngaert [et al.] // Genes Chromosomes Cancer. 2008. V.11. N. 47, pp. 957-964.

\section{References}

1. Sokolova M.A. Sovremennyj predstavleniya o «klassicheskih» $\mathrm{PH}$ - nagativnyh hronicheskih mieloproliferativnyh zabolevaniyah [Modern ideas about the "classical" PH - nagative chronic myeloproliferative diseases]. Clinical Oncohematology, 2010, №3 (3), pp. 235-242.

2. Ispol'zovanie geterodupleksnogo analiza I pirosekvenirovaniya $\mathrm{v}$ algoritme diagnostiki istinnoj policitemii, associirovannoj s somaticheskimi mutaciyami v 12 ekzonegena JAK2 [Using heteroduplex analysis and pyrosequencing in the algorithm for diagnosing true polycythemia associated with somatic mutations in exon 12 of the JAK2 gene] / T.N. Subbotina, A.E. Kharsekina, E.A. Dunaeva [et al.]. Laboratory service, 2017, №1 (6), pp. 29-33.

3. An accurate, simple prognostic model consisting of age, JAK2, CALR, and MPL mutation status for patients with primary myelofibrosis / U. Rozovski, S. Verstovsek, T. Manshouri [et al.] // Haematologica, 2017, V. 102, N. 1, pp. 79-84.

4. Genome-wide copy number alterations detection in fresh frozen and matched FFPE samples using SNP 6.0 arrays / M. Tuefferd, A.D. Bondt, I.V.D. Wyngaert [et al.] // Genes Chromosomes Cancer, 2008, V.11, N. 47, pp. 957-964.

\section{ДАННЫЕ ОБ АВТОРАХ}

Курочкин Дмитрий Владимирович, бакалавр 3 курса

Федеральное государственное автономное образовательное учреждение выстего образования "Сибирский федеральный университет» Свободныий проспект, 79, г. Красноярск, 660041, Российская Федераџия dmitrij_kurochkin_98@mail.ru

Карнюшка Анастасия Александровна, магистр 2 курса Федеральное государственное автономное образовательное учреждение выстего образования «Сибирский федеральный университет» Свободный проспект, 79, г. Красноярск, 660041, Российская Федераџия miss.anastasia-box@yandex.ru

Петриченко Татьяна Юрьевна, студент, лечебный факультет ФГАОУ ВО Красноярский государственный медичинский университет имени профессора В.Ф. Войно-Ясенецкого Министерства здравоохранения Российской Федерации 
ул. Партизана Железняка, 1, г. Красноярск, 660022, Российская Федерачия

tanyapetry@gmail.com

Субботина Татьяна Николаевна, к.б.н., доцент, заведующая НПЛМГМИ ФГАОУ ВО СФУ

Федеральное государственное автономное образовательное учреждение выстего образования «Сибирский федеральный университет»; Федеральное государственное бюджетное учреждение «Федеральный Сибирский научно-клинический иентр Федерального медико-биологического агентства»

Свободный проспект, 79, г. Красноярск, 660041, Российская Федераџия; ул. Коломенская, 26, г. Красноярск, 660037, Российская Федераиия

stn.25@mail.ru

Гаркуша Татьяна Андреевна, ординатор

ФГАОУ ВО Красноярский государственный медицинский университет имени профессора В.Ф. Войно-Ясенеикого Министерства здравоохранения Российской Федерации; КГБУЗ Красноярское краевое патолого-анатомическое бюро

ул. Партизана Железняка, 1, г. Красноярск, 660022, Российская Федерачия; ул. Партизана Железняка, 3д, г. Красноярск, 660022, Российская Федераичия sapfiradracula@yandex.ru

Хазиева Анна Сергеевна, врач-гематолог КГБУЗ Краевая клиническая больнииа ул. Партизана Железняка, 3А, г. Красноярск, 660022, Российская Федерачия haas86@mail.ru

Хоржевский Владимир Алексеевич, к.м.н., заместитель главного врача по патологоанатомической работе КГБУЗ Красноярское краевое патолого-анатомическое бюро ул. Партизана Железняка, 3д, г. Красноярск, 660022, Российская Федерачия vladpatholog@yandex.ru 


\section{DATA ABOUT THE AUTHORS}

Kurochkin Dmitry Vladimirovich, bachelor 3 year

Siberian Federal University

79, Prospect svobodnyy, Krasnoyarsk, 660041, Russian Federation dmitrij_kurochkin_98@mail.ru

Karnyushka Anastasia Aleksandrovna, Master 2 years

Siberian Federal University

79, Prospect svobodnyy, Krasnoyarsk, 660041, Russian Federation miss.anastasia-box@yandex.ru

Petrichenko Tatyana Yuryevna, student, medical faculty

Krasnoyarsk State Medical University named after professor V.F. Voyno-Yasenetsky Ministry of Health of the Russian Federation

1, Partizan Zheleznyak, Krasnoyarsk, 660022, Russian Federation tanyapetry@gmail.com

Subbotina Tatiana Nikolaevna, Ph.D.

Siberian Federal University; Federal Siberian Research Clinical Centre under the Federal Medical Biological Agency

79, Prospect svobodnyy, Krasnoyarsk, 660041; 26, Kolomenskaya str., Krasnoyarsk, 660037, Russian Federation

stn.25@mail.ru

Garkusha Tatyana Andreevna, resident

Krasnoyarsk State Medical University named after professor V.F. Voyno-Yasenetsky Ministry of Health of the Russian Federation

1, Partizan Zheleznyak, Krasnoyarsk, 660022, Russian Federation sapfiradracula@yandex.ru

Khazieva Anna Sergeevna, hematologist

Regional Clinical Hospital

3A, Partizan Zheleznyak Str., Krasnoyarsk, 660022, Russian Federation haas86@mail.ru

Khorzhevsky Vladimir Alekseevich, Ph.D in Medical Science, deputy chief physician for autopsy work

Krasnoyarsk regional patho-anatomical bureau

3D, Partizan Zheleznyak Str., Krasnoyarsk, 660022, Russian Federation vladpatholog@yandex.ru 